\title{
REHABILITATION OF LANDFILLS. NEW FUNCTIONS AND NEW SHAPES FOR THE LANDFILL OF GUIYANG, CHINA
}

\author{
Anna Artuso ${ }^{1}$, Elena Cossu ${ }^{1, \star}$, Liang $\mathrm{He}^{2}$ and Qirui She ${ }^{2}$ \\ ${ }^{1}$ Arcoplan Associates, via Beato Pellegrino 23, 35137 Padova, Italy \\ ${ }^{2}$ Beijing Environment Sanitation Engineering Group Co. Ltd, Jinghuan building, n. 15, Beihuqu Road, Chaoyang District, Beijing 100101, \\ China
}

Article Info:

Received:

6 May 2020

Accepted:

4 June 2020

Available online:

23 July 2020

Keywords:

Waste architecture

Landfill

Community

Landmark

Urban park

\begin{abstract}
The enlargement of a modern landfill may provide an opportunity to intervene with large-scale projects and thus restore spaces for community use and potentially providing an added value. Based on these premises, the intervention on the Guiyang landfill in China has been developed focussing on the possibility of future reclamation of the site under construction during the design stage by applying an approach that takes into account future use from a technical and, more importantly, economical perspective from the outset. The design proposal has been developed following analysis of these elements: landscape and territory (predominant features of the area, naturalistic features to be preserved, optimization of the interrelationship between the adjacent areas and functionality of the territory); analysis of the residential, infrastructural and productive systems (fundamental in ascertaining the size of the catchment area of potential users). The landfill mining intervention planned in the area allows a more efficient operation of the landfill and has been studied to redesign the site in terms of morphological shapes. Indeed, the project suggests the use of the mass of waste as a plastic element for the reconstruction of a redeveloped landscape according to the shape required by the new configuration of the area. In view of this consideration, in this case study, the typical shape of a landfill is abandoned and the site has been reshaped according to the design of the Chinese landmarks in the surroundings. The area has been conceived as a new green space and defines the role of the landfill site as an Environmental Education Centre and a recreational urban park for public uses, located close to a highly urbanized area. This project design was developed in the context of the ROLES initiative funded by the Italian Ministry of Foreign Affairs in the framework of the Scientific and Technological Cooperation Agreement between the Government of the Republic of Italy and the Government of the People's Republic of China. ROLES was coordinated by Raffaello Cossu (University of Padova, Italy) with the collaboration of Roberto Raga (University of Padova, Italy) and Dongbei Yue (Tsinghua University, China). ROLES (Remediation of Old Landfills for Environmental sustainability and final Sink) proposes an innovative approach to landfill reclamation, analysing in depth the issue of functional requalification, i.e. the possibility of enhancing the valorisation of landfill surfaces for specific uses aimed at ensuring environmental and landscape sustainability.
\end{abstract}

\section{INTRODUCTION}

In designing or remediating a landfill, a common approach consists in concealing the facility from view and from the public conscience. Landfill is an eyesore which society would prefer to ignore. However, to merely conceal a landfill is not a recommended strategy as society should be forced to acknowledge it exists, what the implications are, and why it is destined to remain. Moreover, the transformation of a large piece of land into a green mound hav- ing scarce value for the surrounding community is not an effective solution (Gowar, 2016).

Landfills have long been viewed as highly engineered spaces driven by economic, technical and health concerns, whilst giving scarce consideration to aesthetics or design - other than concealing them from view. These sites may however represent an opportunity for development through application of landscape architecture aimed at highlighting waste issues in current society (Engler, 1995).

The role of the architect is to determine the conditions,

\section{* Corresponding author:}

Elena Cossu

email: studio@arcoplan.it 
problems and challenges of the site and to identify current or future users, assessing the most favourable approach and design best suited for the site concerned. Analysis should unfailingly represent the first step and underlying basis for all projects (Grudziecki \& Buachoom, 2016).

A landfill might be integrated into its topographic and ecologic environment instead of remaining an island - set apart, and should be seen as design opportunity and not just a place we isolate and ignore (Jenkins, 2016).

The development of new structures on top of landfills is associated with a series of challenges, largely due to the composition of these facilities. Therefore, transformation of landfill sites is closely linked to factors including waste composition and age, degree of compaction and local climate. Taken together, these determinants will establish the design limits and dictate the type of structure to be built on the landfill (Grudziecki \& Buachoom, 2016).

The majority of landfill transformations are related to closed plants, although reclamation works performed on a landfill will have a far greater chance of success when studied and developed during the stage of active management of the landfill (during the construction stage, waste deposition or at the time of a potential extension) (Artuso et al., 2018). Indeed, the use of new wastes as a plastic material with which to mould the shape extends the pool of potential uses assigned to the project, and provides greater freedom in reinventing the final configuration of the area, in addition to facilitating important budgetary savings in terms of material to be delivered to modify the structure of the site. These concepts are however deemed extremely innovative when compared with common practice as they dictate a change in the terms of the project: we are no longer the designers of mere landfills, but rather of community spaces (Artuso \& Cossu, 2018a).

The requalification of a landfill provides an opportunity to undertake qualified territorial reorganization work in which the procedures applied in plant management and redevelopment of the environment may constitute a key factor in effective rezoning of the area. The available options geared towards renewing the functional status of the area undergo a decision process to assess the most appropriate end use in terms of territorial reorganization, impact on the landscape, environmental sustainability and public consensus (Artuso \& Cossu, 2018b).

The case study of Guiyang landfill has been studied and developed in line with all the above principles.

\section{PRELIMINARY ANALYSIS}

\subsection{General location, current planimetric layout and waste body characteristics}

The landfill, identified as a case study, is located in the Guizhou province, south-west of the People's Republic of China, and is located close to Guiyang, the capital province and important metropolis of almost 4,500,000 inhabitants. The land is largely mountainous with plains to the east and south and hills in the western part of the province (Figure 1).

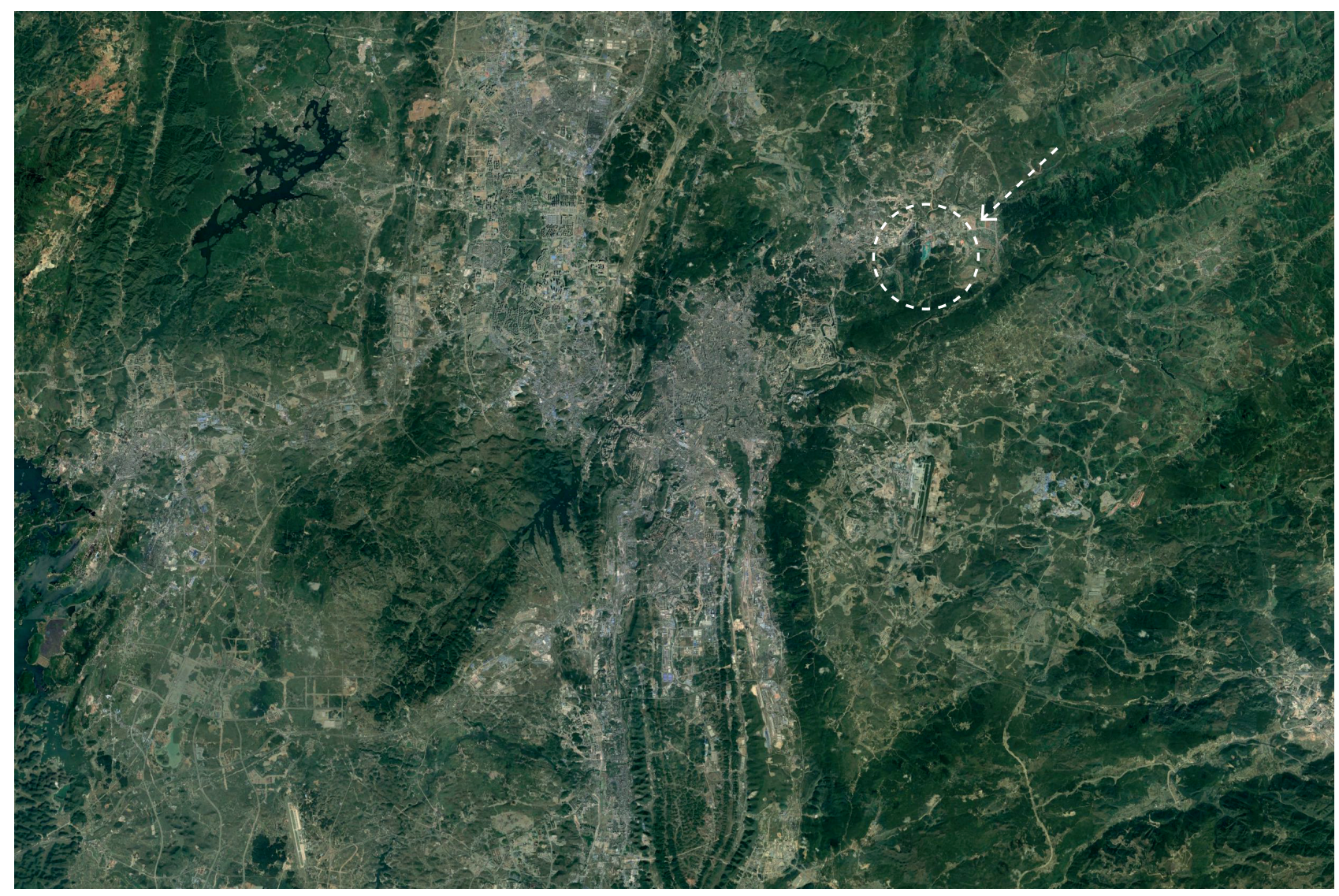

FIGURE 1: Orthophoto of the city of Guiyang and identification of the area for intervention. 
More precisely, the study area is located in the west part of the metropolis, on the boundary of an industrial and productive area and in between a new expanding area and an uncontaminated natural area of woodland (Figures 2-3).

The study domain comprises an extensive surface area on the east side, indicated as an area for waste storage. This section could be considered for possible expansion of the landfill with a view to a wider development of the area. In the immediate future, this area could be employed as a selection, sorting and temporary storage point for materials excavated by landfill mining. Subsequently, it could be exploited for the construction of new landfill sectors in line with the intention to dispose of waste according to a morphology established by the general design.

The main vegetation is arboreal with a predominance of pine forests. The area is flanked on the west side by the railway. Figure 4 shows the current layout of the area.

The landfill has an average height of approx. 25-30 meters above ground level, with an altitude of $1090 \mathrm{~m}$ above sea level. The landfill is currently operational. It is expected that approx. $10 \%$ of the existing landfill volume will be affected by a landfill mining project, in the area identified in Figure 4 with the letter "B". The landfill mining work envisaged will facilitate the creation of new volumes in the existing landfill and be linked mainly to the removal of deposited wastes, to the potential separation of fractions with recovery of materials and/or energy, and disposal of the residues in a new landfill. The work will require prelimina- ry in-situ aeration treatment in order to stabilise the waste mass and allow excavations to proceed safely. As described subsequently, the landfill mining work, to be carried out solely on a small section of the landfill, will afford the possibility to build up waste embankments in line with a specific design with a view to future re-use of the site. The area concerned is currently closed by a final HDPE cover that will be removed.

\subsection{Landscape area of reference: environmental do- minant elements and landmarks, green system and protected areas}

An analysis carried out using geolocation tools available on the web identified a series of natural signs typical of the area that are considered unique landmarks in the landscape. In particular, the terracing, used for the cultivation of sloping rice, is a distinctive feature of the area. This cultivation technique marks the territory by drawing strips of different shades of green subjected to chromatic changes according to the seasons (Figure 5).

Another landmark characterizing the landscape is determined by the mountainous hill system in which reliefs appear as isolated pinnacles deeply engraved by river valleys (Figure 6).

Several protected natural areas have been identified close to the study area. Today, the forest pavement of the Guizhou plateau has been largely replaced by secondary shrubland or by scattered forest associations consisting of

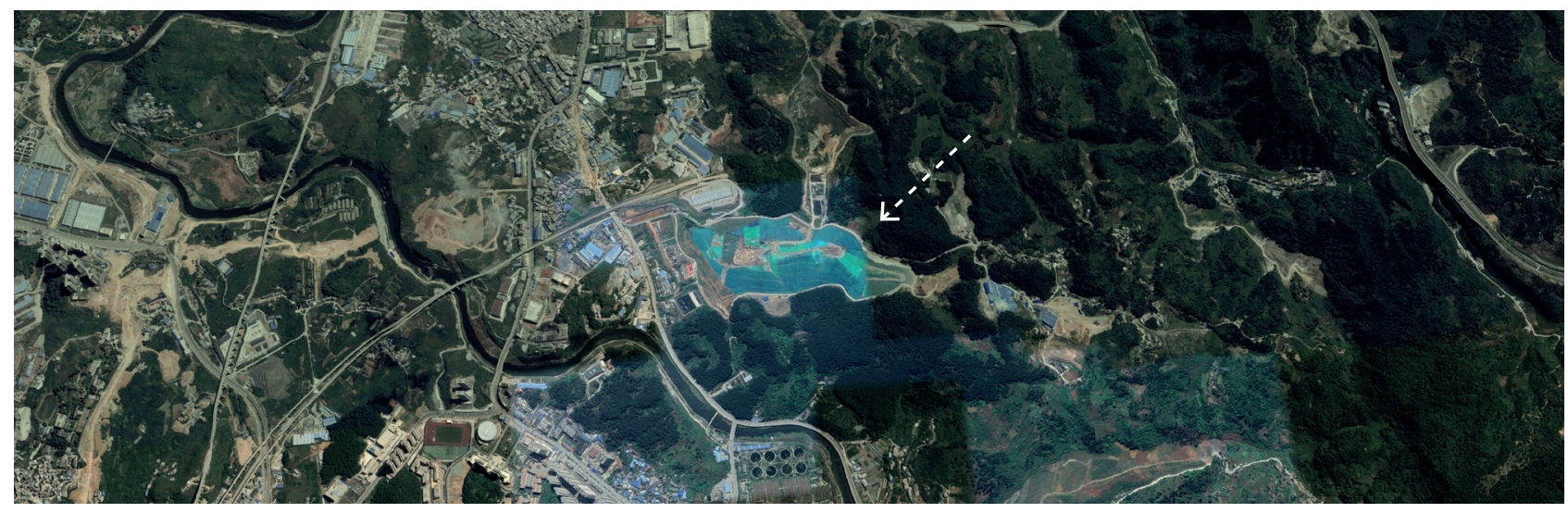

FIGURE 2: Orthophoto of the area highlighting integration of the plant into the original forest.
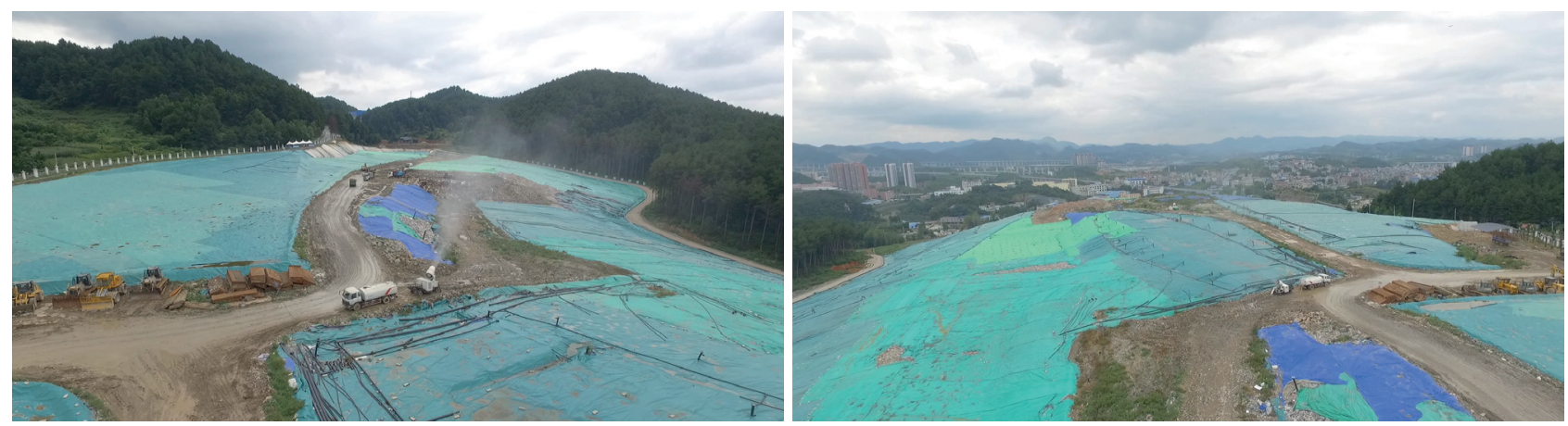

FIGURE 3: View of the landfill towards the surrounding forest and towards the city. 


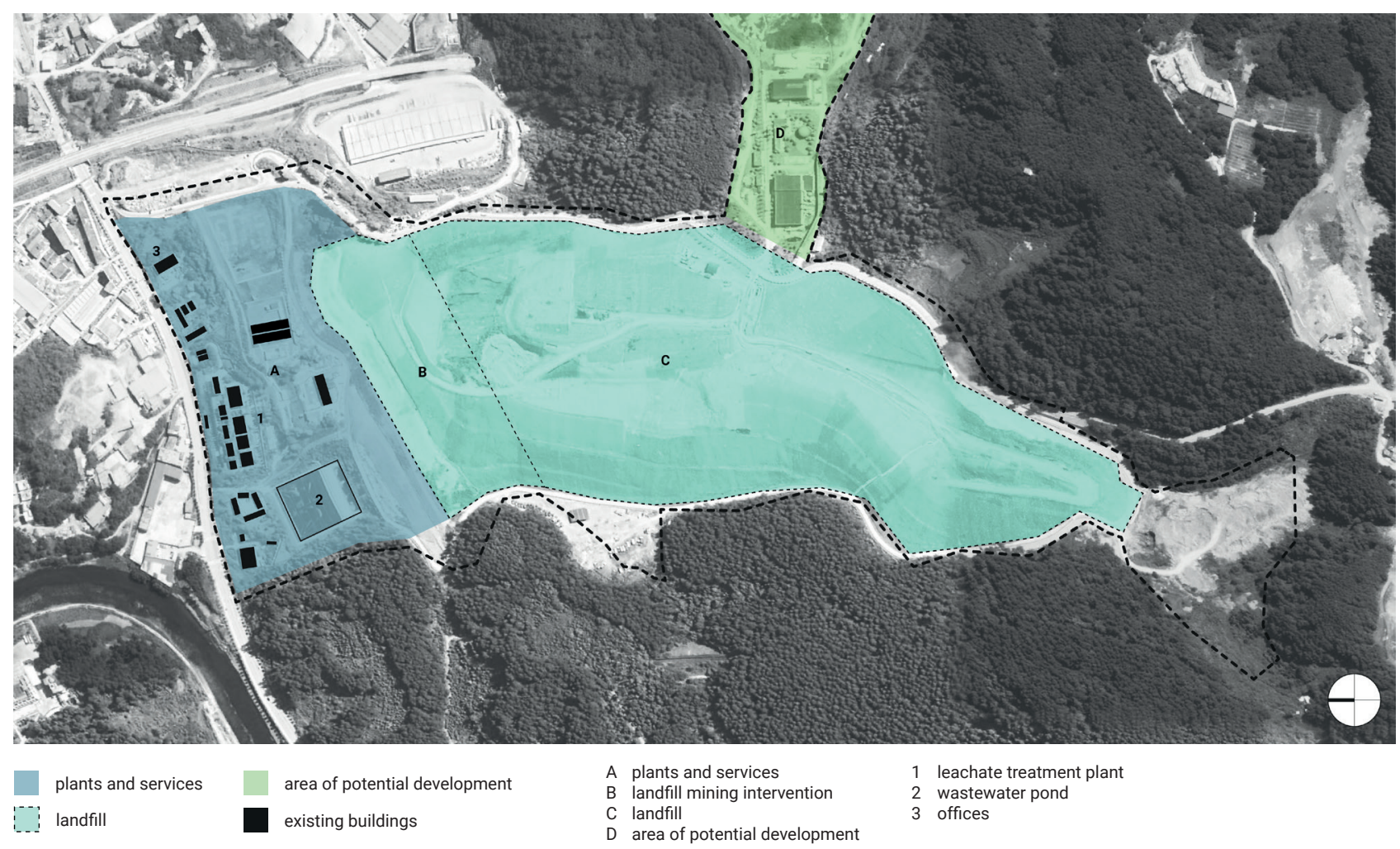

FIGURE 4: Orthophoto showing a schematisation of the current status and identification of the operational areas.

species belonging to the Ericaceous family. Patches of original forest remain within protected areas, but elsewhere it has almost completely disappeared, with the exception of limited areas covering the most remote and inaccessible calcareous hills.

The overlap of the green system with the urban system highlights the availability of large areas of public green within the urban fabric, for a total area of 5379.71 hectares. These are mainly urban parks conceived as inclusions of natural forests within the city. Qian Ling Shan Gong Yuan, Guanshanhu Park, Chang Po Ling Forest Park, and Hotspring Park are some of the great "green lungs" inserted into the metropolitan fabric, for leisure use, sports and other activities.

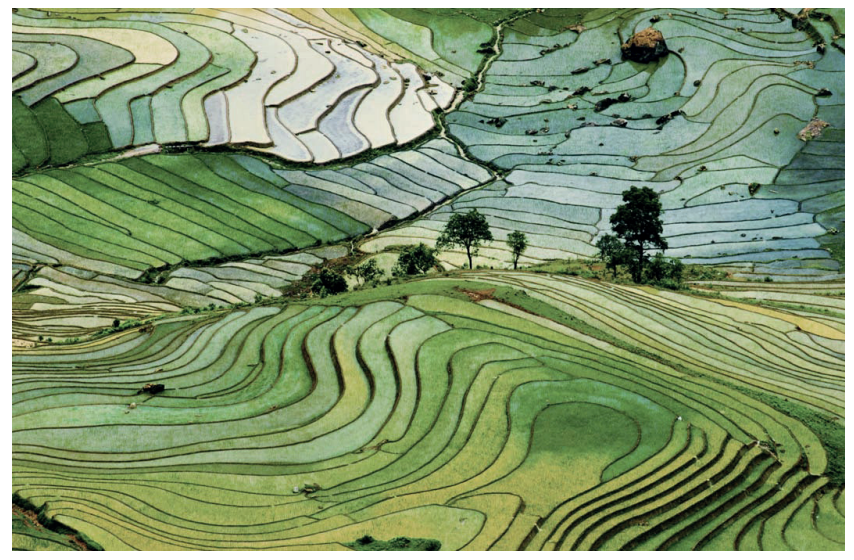

On observing the study area in Figure 7 and imagining future development in the urban area resulting in an increased population, it is evident that the landfill is located in a strategic position suited for use as a green area for citizens living in the north-east zone of the city, featuring the same standards proposed in the large natural parks described above.

\subsection{Analysis of the settlement system, identification of expansion areas and residential catchment area}

This analysis probably represents the most important phase of preliminary characterization and facilitates an understanding of the extent of potential users of the area, taking into account distance from the main urban centres to be linked to the project.

FIGURE 5: Major Landmark: terracing as a characteristic and univocal sign of the Chinese agrarian landscape. 

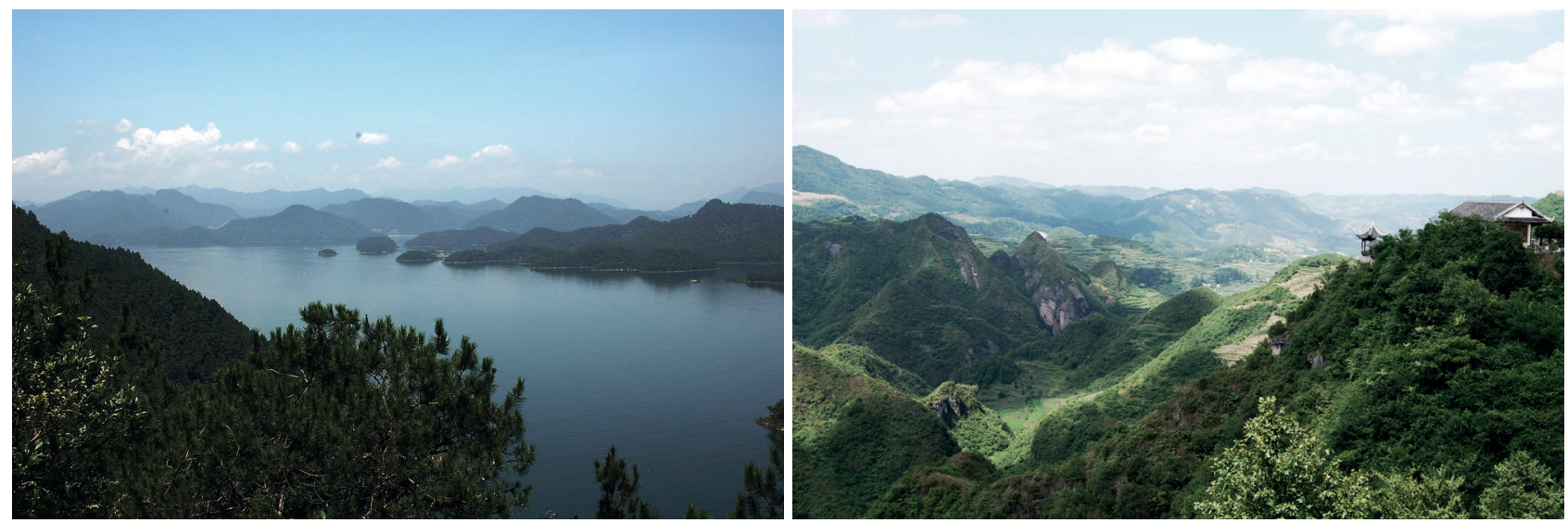

FIGURE 6: Typology of hilly and mountainous features with both isolated and grouped peak.

The landfill concerned is located in a highly urbanized area, close to a city with a high population density and, as already mentioned, forms part of a new expansion area (Figure 8).

The location of the plant allows us to hypothesize reuse of the area as an urban park for the new expansion area, where the concept of park is borrowed from the existing type, namely that of the natural biotope.

The overlapping of maps also allowed the landfill position to be related to the university and research centres in the city, with a view to considering the park a Centre for en- vironmental education and sustainable research (Figure 9).

The proximity of an extended educational centre located in the northwest, less than $5 \mathrm{~km}$ from the planning area, increases the range of proposed activities for the park, in synergy with other educational centres in the city, hosting several higher education centres and large universities such as Guizhou University, Guiyang Medical University, Guizhou Normal University, Guizhou University for Nationalities and Guiyang College of Traditional Chinese Medicine. The province hosts approx. 200 institutes of natural sciences.

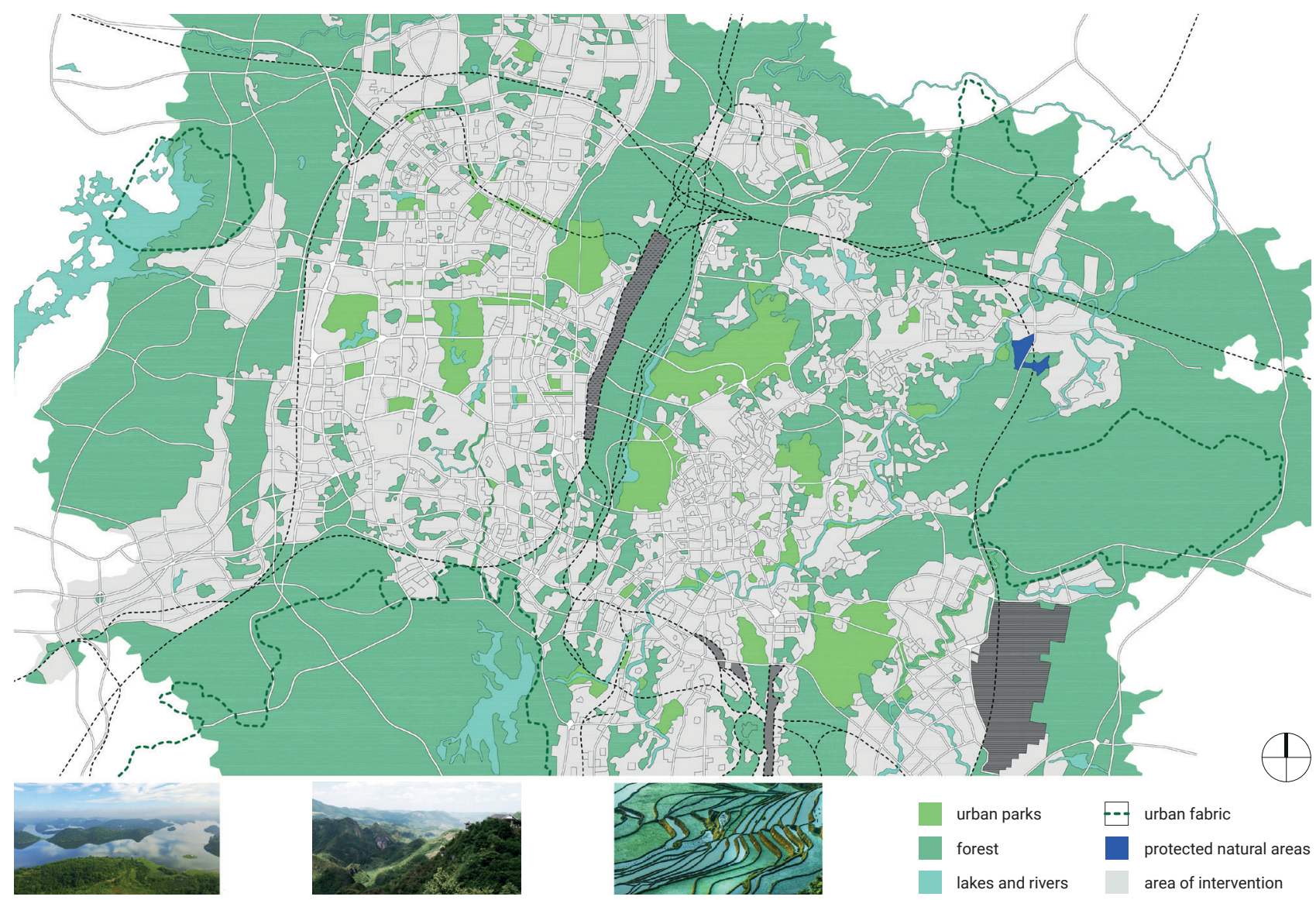

FIGURE 7: Analysis of urban green spaces and natural park. 


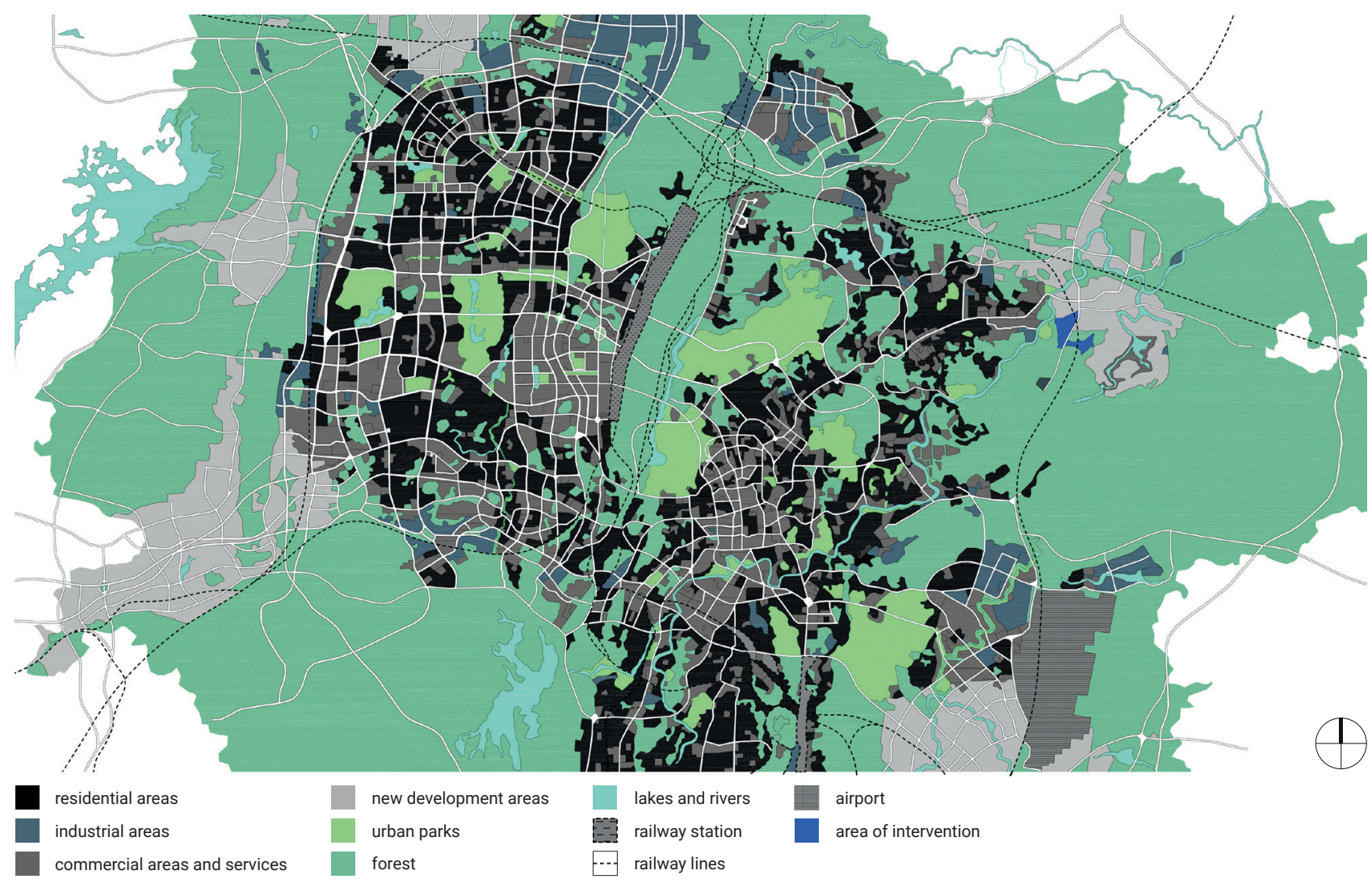

FIGURE 8: Territorial context.

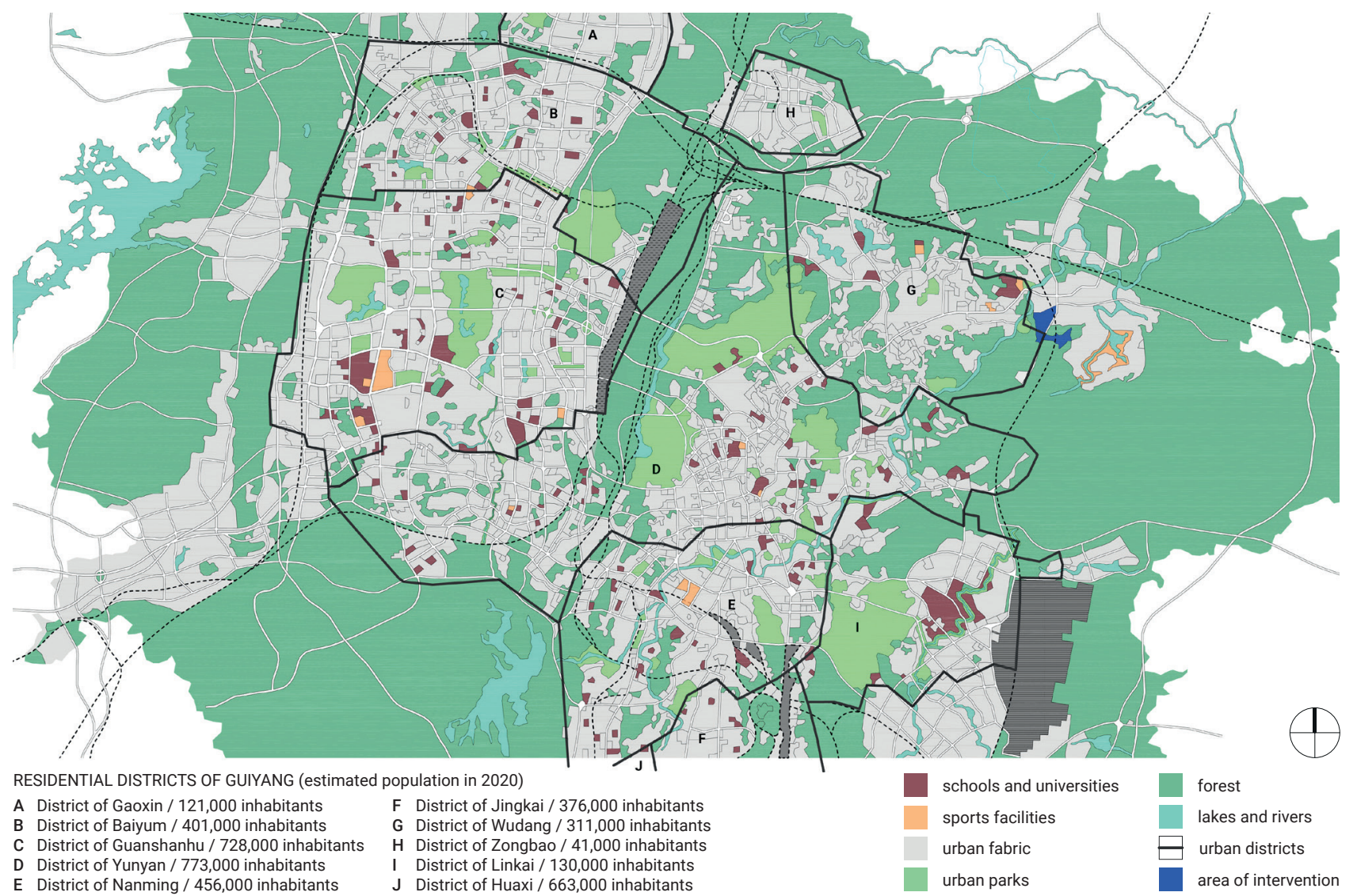

FIGURE 9: Analysis of the residential and infrastructural system. 
The analysis reveals the scarce presence of sports facilities in the area adjacent to the landfill.

The proximity of an extended educational centre located in the northwest, less than $5 \mathrm{~km}$ far from the planning area, increases the possible activities to be proposed in the park, in synergy with this and others educational centre of the city. There are several higher education centres and great universities such as Guizhou University, Guiyang Medical University, Guizhou Normal University, Guizhou University for Nationalities and Guiyang College of Traditional Chinese Medicine. The province has about 200 institutes of natural sciences.

The analysis shows few services for sports facilities in the area adjacent to the landfill.

\section{HYPOTHESIS FOR REQUALIFICATION OF THE LANDFILL AREA}

\subsection{Planimetry, volumetric features and general de- scription of the area}

Analysis of the aspects previously described represented the starting point for development of the requalification project; the final aspect to be achieved is shown in Figure 10.

The planned landfill mining project will only interest a portion of the landfill, allowing wastes to be re-disposed according to a well-established criterion.

The ultimate re-use of the area will be completed within a significant time frame and has been conceived to promote an immediate co-existence with the ongoing operations of active landfill management. Re-use of the area is inten- ded to be implemented immediately, with subsequent sections being added once they become available. The overall project provides for the start-up of a series of future scenarios in the short, medium and long-term, ranging from the initial phase characterised largely by excavations and re-embankment of earth and wastes, to the final phase which will witness the development of construction works (internal viability, pathways, playgrounds, sports) aimed at promoting use of the entire area.

Assessment of the environmental aspects of the area identified the terraced cultivation of rice as the most characteristic landscape element of the area, which has been adopted as a connecting element between the most natural part of the park and the facilities area, including an environmental centre. The park will be comprised of a wellorganized green area (the current facilities area), including a centre for environmental education, and a more natural area conceived as an urban forest in line with local parks used as a model.

Terracing is configured as a compositional element of landscape design and planted on different levels using a series of diverse species to create bands of different shades of green.

Terracing will be appropriately designed in terms of slopes, width, and passage space for earth moving machinery, in order to facilitate disposal of new waste and, ultimately, placing of a final landfill cover. Terrace width will be selected in order to allow people to carry out all the activities envisaged in the context of the park.

Terraces can be partially planted with medicinal plants traditionally used in Chinese medicine.

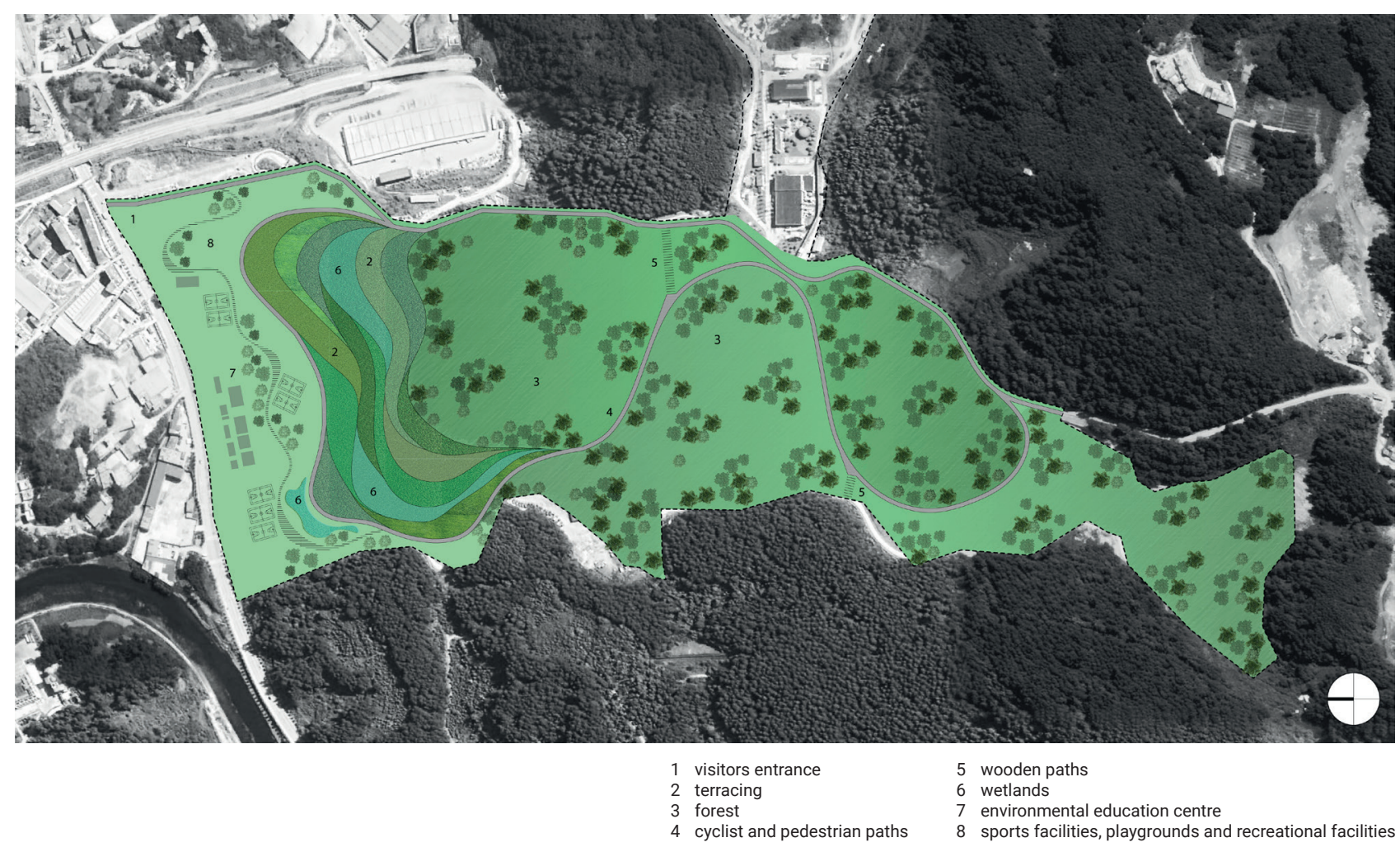

FIGURE 10: Map of the general project of the area. 
Landscape requalification also provides for the creation of a wet area close to the plant. More precisely, it is suggested that excavation should be carried out to partially exploit the existing leachate collection tank, suitably modified to acquire a more natural shape.

The potential creation of a lake for the construction of a reservoir will be evaluated; indeed, the latter, in addition to serving as a catchment area for rainwater, could contribute towards re-naturalization of the site and park.

A re-naturalized lake significantly enhances the environment, acting as a pleasant stop and observation point at any time of the year; it allows creation of a real aquatic garden, with a strong naturalistic imprint, which would be quickly populated by a variegated aquatic microfauna (butterflies, swallows, dragonflies, frogs, salamanders). The lake would as a storage tank for the irrigation system in addition to increasing the value of the landscape.

\subsection{End-use destinations for the area and the Envi- ronmental Centre}

The project for functional restoration of the landfill, characterized by successive phases, foresees a functional reuse of the entire area as a research and environmental education park, conceived as a large "open-air laboratory", in the context of which each area has its own specific function.

This proposal stems from analysis of the territorial, social, landscape and cultural aspects of the area, but which takes into account enhancement of the site also in view of its potential scientific value acquired over time as a landfill, and the possibility of positively exploiting some features of the plant.

The end result will be a well-equipped area from an ecological point of view to be used as a place of environmental dialogue where experiences, resources, development and activities are shared (Table 1).

Although the functions provided may differ, they are all linked by the common target of " $100 \%$ recovery", conceived as recovery of materials, energy, water and land. Therefore, the park, conceived as a leisure space to serve the city, acquires a social and educational role aimed at promoting environmental awareness rather than delimiting the area merely for recreational purposes.

The final project would include all existing lots, the landfill area interested by landfill mining and the service area and related buildings, including the plants. The area of potential expansion inside the property that is not currently exploited (indicated as " $D$ " in Figure 4) could also be included.

The requalification project is integrated into the territorial context, respecting the morphology of the surrounding landscape and recreating continuity of the space in lines and shapes. Furthermore, the requalification project establishes the original function of the territory by increasing its value and distributing in a composite manner a plurality of functions: educational, social, cultural (environmental protection awareness) and recreational (green areas for technical visits).

From a technical-scientific point of view, the area affected by the environmental requalification project is ai- med at recovery of a landfill area through construction of a multidisciplinary research park of potential interest both for the population and technical-scientific concerns associated with universities (collaboration with laboratories, thesis students, research), research centres (including foreign ones), farms, companies, pharmaceutical companies, etc.

Buildings housing the plants are readily adaptable for use in the Environmental Education Centre, conceived as the "eco-sustainable" purpose-designed heart of the park (including green area, paths, furniture, benches, etc.). Indeed, the design project envisages a green area in which recycled materials will be employed. Benches, pedestrian paths, play areas will be built and assembled using recycled plastic or wooden materials, some of which created by the park users. The area would thus become a sort of large outdoor laboratory with areas dedicated to recycling techniques. Spaces are envisaged for construction of the objects, and artistic laboratories (both outdoors and inside the Centre) - Figure 11.

A dedicated space could also be provided for thematic conferences and seminars. The park could be made available to associations, public concerns, consortia, schools, competitions and other events.

The purpose of the park will be to demonstrate that waste, if properly managed, can have a second life. In this perspective, materials originating from separate collection will be recycled to form objects for games, decorative elements, sculptures, coloured aggregates for paths, etc.

From an energy requalification point of view, recovery of the biogas produced within the landfill will be used in the lighting of the park.

This requalification project and creation of a green area is aimed at restoring the original forestry cover of the Guizhou plateau that has largely been replaced by a secondary scrubland.

A free design of the green is therefore proposed, with associations of forest species typical of the seasonal tropical forests (Sterculia, Erythrina, Ficus, Eugenia and Helicia) or secondary forests (Albizzia, Rhus, Cornus, Liquidambar), present at latitudes similar to those of the landfill.

The possibility of inserting artificial tanks in the terraces to re-propose a typical rice field landscape will be evaluated.

Short sections of bamboo forest will be designed at selected points along the paths within the project, in order to underline the oriental atmosphere. Bamboos grow rapidly in height, filtering light and wind, yielding unique light and sound effects. In this context, the bamboo forest will represent an element of acoustic ecology, intended to reduce noise pollution and therefore in line with the sustainability concept of the park.

\section{FUTURE PERSPECTIVES: PROJECT-STRA- TEGIC INDICATIONS}

The municipal solid waste landfill should be integrated into the design project to maintain a functional use rather than its originally intended use. It should not be viewed as a mere designated use of the area, but as a process of development heralding the advent of "new designated uses". 


\section{ACTIVITY}
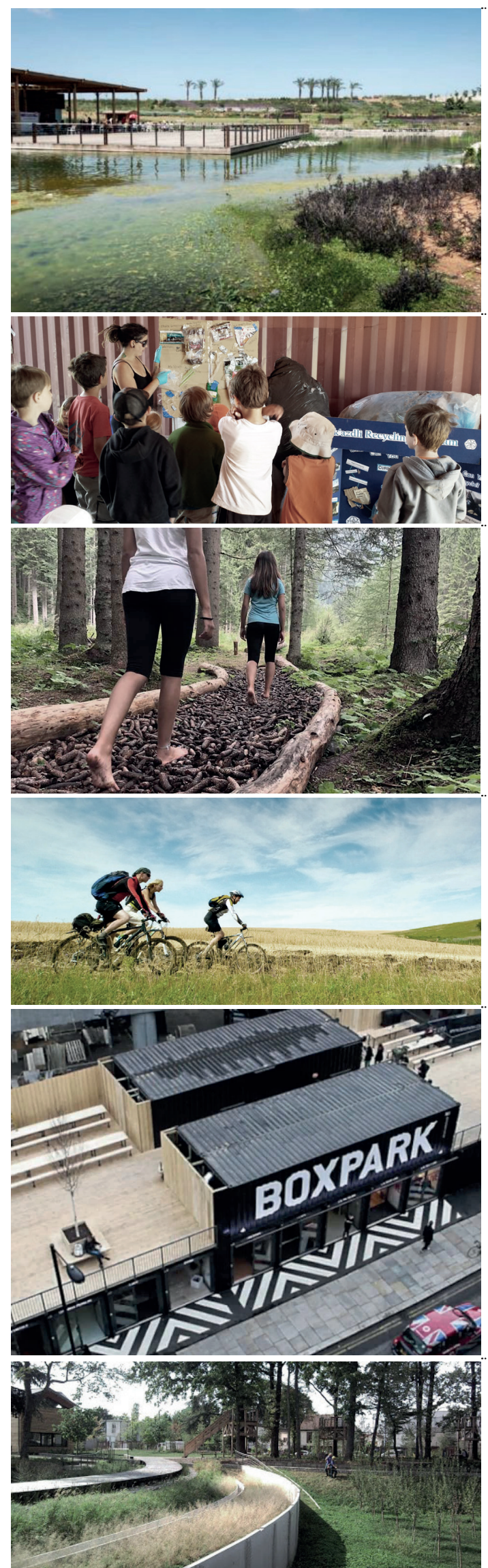

COMMENT

The environmental centre is envisaged as a leisure centre focused on the new practices of everyday life, immersed in a low-tech technology universe that employs natural in construction of devices through sustainable processes respecting the pre-existing natural equilibrium

Numerous events can be organized: repair workshops for small household appliances, conferences on environmental sustainability, natural cosmetics courses, workshops on the recovery and recycling of objects, gardening, art exhibitions, etc

The centre surroundings will be developed to provide a pleasant area in which to carry out outdoor activities, with the possibility of using the adjacent wet areas, and will form the gateway to the natural park. In line with the philosophy of the project, organic waste produced inside the Centre (for example Bar) will be composted and used as an agricultural soil conditioner in the park.

All planned activities will be aimed at involving first of all schools (primary and secondary) and university students, in addition to the general population. The Centre will be equipped with specific areas for workshops, seminars, practical lessons designed to cater for a series of indoor and outdoor activities.

The park as a whole is designed to promote a culture of recycling and increase environmental awareness amongst the population. Accordingly, some elements within the area may be manufactured using materials recovered from landfill mining activities, as well as through the contribution of park visitors themselves. Lookouts, stopping points and equipped areas, air-and-wildlife watchtowers, benches, sensory paths can become practical topics to propose and develop in the context of competitions, workshops or various activities with a view to ensuring the local community becomes an integral part of the requalification process. The park project is developed over time and also realized through the contribution (intellectual and manual) of visitors themselves to boost a sense of belonging.

In an extremely natural context, sports can be practiced on fitness itineraries in the equipped areas. The park will be crossed by dirt tracks or paths made from natural materials to promote a full usability of the area. Once again with a view to reusing the materials found on-site (wood, stone, etc.) gym stations along the fitness itineraries and bike and mountain bike routes will be realized

The architectural quality of the buildings clearly contributes towards enhancing the pleasurability of the project. The language of architecture and an appropriate choice of shapes and materials will promote the salience of spaces and functions, in addition to providing a more complete image of the entire environmental park.

To reduce the economic investment on the buildings and adhere to the philosophy of the whole project, it may be of interest to assemble a series of cargo containers, exploiting a versatile construction system that is well suited to the needs of the park. The containers, assembled and revisited from an architectural point of view, could be proposed as supporting spaces for Centre activities and, in view of their modularity, could be extended as required.

In this way the space can be used to meet a range of varying needs. These ideas may indeed prove useful as, in the majority of cases the empty containers are stored one on top of the other in huge dedicated areas, with no further plans for reuse.

Several experimental activities ranging from phytotreatment to greenhouses fed with biogas may be developed. An infinite number of experimental activities aimed at providing alternative energy strategies or sustainable water management may be devised and established within the area. 


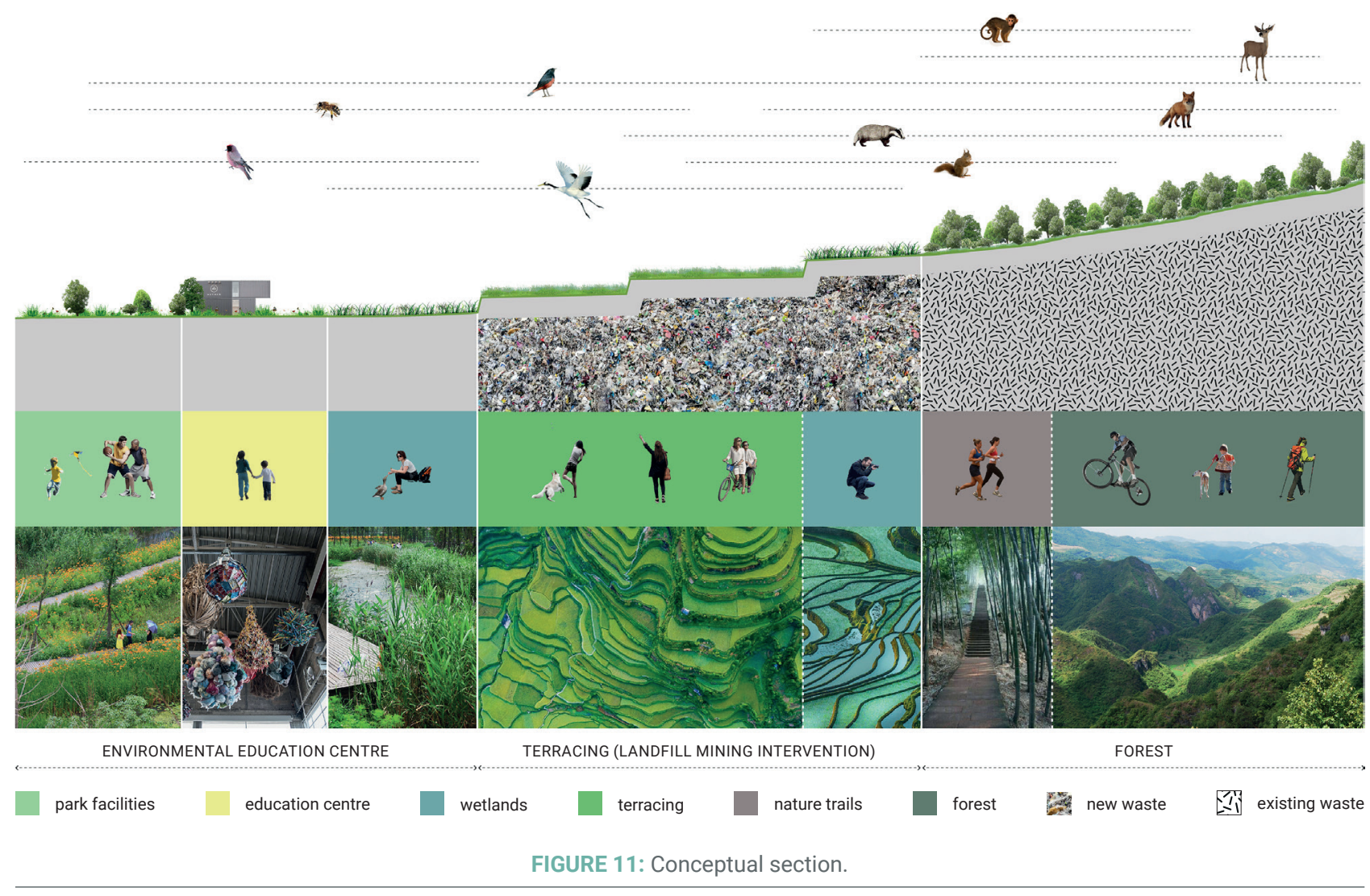

The project-strategic indications referred to in this final paragraph are intended to provide a series of ideas to be evaluated and investigated in a possible future phase of the project:

- RECOVERY OF BUILDINGS AND EXISTING WORKS: Proposal of a graphic-architectural restyling project to improve the visual impact of buildings through a minimal repercussion on the built-up area (for example applying giant alphanumeric lettering on the fronts of prefabricated buildings). The use of large numbers and colourful letters painted on portions or corners of buildings would, at limited cost, render prefabricated concrete buildings more aesthetically pleasing, as well as contributing to the legibility of spaces and functions within the systems. Ideas for improvement of structure presentation may include: giant lettering used as signs or "displays", the use of coloured paints on portions of fronts, numbers printed off-scale on high-speed doors, "poor" recycled materials to be used as a wall covering. Properly renovated containers could be used, in line with the philosophy of the park.

- WATER RECOVERY AND CONTAINMENT: Study of the entire rainwater containment and collection system providing for the recirculation of rainwater as water supply for the park and irrigation. Provision of a collection tank with the dual function of storing and creating a wet area to complete landscape intervention, useful in promoting the repopulation of fauna;

- PLANNING OF AN IMMEDIATE SITE RECOVERY: Landscaping during landfill aftercare, making the facility better visible and open to visitors. Creation of a wel- come point for the public through identification and optimisation of suitable existing spaces not currently in use. Devising of an itinerary for a complete guided tour of facilities. Routes within the area will be studied in order to not hinder vehicle operations and activities and ensure visitor safety. Itineraries will be realized using horizontal signs set out on the ground using large stripes and coloured arrows, and foresee the use of small fences, docks and / or sidewalks, stop areas to guarantee maximum visitor safety. Routes will be appropriately signposted and explanatory photographic panels provided in areas not open to the public for safety reasons. Routes within the Centre will be designed to ensure ready accessibility and usability of the area, with the possibility of crossing from one selected itinerary to another. The fenced green area near the exit will be integrated and used as a space for outdoor lessons in the summer season, educational workshops, etc.

\section{CONCLUSIONS}

Downstream of the outcomes of preliminary territorial analysis, the planning and design project has been developed with the aim of fostering a harmonious insertion of the intervention in the local context, in respect of the morphology of the surrounding landscape, and recreating the essential forms and lines of spatial continuity. This project for reuse of a landfill will restore the territory to its natural vocation, moreover providing an added value and meeting the requirements of the local community by bridging a potential gap in the lack of infrastructures. Furthermore, it will 
provide a series of educational, social, cultural and leisure facilities to attract potential users.

The design concept will moreover promote a positive outcome and economies of scale, bearing in mind the economic feasibility of the transformation, and will strive towards creating an "exportable model" for use as a reference project in similar contexts.

\section{REFERENCES}

Artuso, A., Cossu, E., Stegmann, R., 2018. Afteruse of landfills, in Sustainable waste landfilling: Concepts, processes, technologies, edited by Cossu R., Stegmann R., Elsevier publisher, Amsterdam

Artuso, A., Cossu, E., 2018. Afteruse of Landfills. Methodological approach, project requisites and relationship with the surrounding area. Ri-Vista, 16(1), 102-117. https://doi.org/10.13128/RV22973
Artuso, A., Cossu, E., (2018). Reclamation and architectural requalification of an old landfill using in situ aeration, phytotreatment of leachate and energy crops. Ri-Vista, 16(1), 134-145. https://doi. org/10.13128/RV-22992

Biondi, E., 2012. Phytosociology today: Methodological and conceptual evolution. Plant Biosystems - An international journal dealing with all aspects of plant biology, 145 sup. 1, 19-29

De Poli, M., Incerti, G., 2014. Atlante dei paesaggi riciclati, Skira editore, Milano

Engler, M., 1995. Waste landscapes: Permissible metaphors in landscape architecture. Landscape journal, 14(1), 10-25

Gowar, M., 2016. Landfill urbanism. Recovering resources - cultivating community at Hatherley landfill, Thesis dissertation

Grudziecki, J., Buachoom, P., 2016. The landscape architect's guide to the world of solid waste. Thesis dissertation

Jenkins, K., 2016. Installation provides new vision for landfill architecture, by Matt Hayes in Cornell Chronicle. https://news.cornell.edu/stories/2016/02/installation-provides-new-vision-landfill-architecture

Landscape Architecture Europe 2006. Fieldwork. Birkhauser LAE Foundation 